Northà, B. E. \& Norris, F. W. (1952). J. gen. Microbiol. 7, 245-256.

\title{
A Microbiological Assay of Inositol: its Development and Statistical Analysis
}

\author{
By B. E. NORTHAM AND F. W. NORRIS \\ Department of Applied Biochemistry,* University of Birmingham
}

SUMMARY: The assay of inositol has been developed using Kloeckera brevis B 768 and a strain of Schizosaccharomyces pombe. In the assay of Difco Bacto yeast extract it was necessary to supplement the basal medium with an inositol-free preparation from yeast extract. A new assay design has been proposed and the results treated statistically.

A microbiological assay of inositol was described by Woolley (1941) using a strain of Saccharomyces cerevisiae. This was based on the fact that the rate of growth of the organism is stimulated by inositol; but it has the disadvantage that the organism can grow in the absence of an exogenous supply of inositol. A similar method is given by Williams, Stout, Mitchell \& McMahon (1941).

Burkholder, McVeigh \& Moyer (1944) described an assay method using Kloeckera brevis, and Emery, McLeod \& Robinson (1946) have given standard curves for $K$. brevis and Schizosaccharomyces pombe. These organisms appeared to be most suitable for further study since they were unable to grow in the absence of inositol even after prolonged incubation.

Although the inositol content of Difco Bacto yeast extract (DYE) was in itself of small importance it was chosen as suitable test material in the development of the assay since it is rich in substances that stimulate the growth of yeast. Hence a reliable method for the assay of yeast extract might also be expected to give reliable results when applied to other complex biological materials.

\section{EXPERIMEN'TAL}

Tube tests. The usual procedure for microbiological assay was followed, but in place of bacteriological tubes, flat-bottomed tubes (Samco), $4 \times \frac{3}{4}$ in., were used. Tubes were selected so that their internal diameter was within the limits 1.66 and $1.72 \mathrm{~cm}$.

Test and standard solutions were added to the tubes from a $5 \mathrm{ml}$. microburette, and the volume made up to $3 \mathrm{ml}$. with water; $3 \mathrm{ml}$. of basal medium at double strength was added by means of an automatic pipctte, similar in construction to that described by Ridyard (1949).

The tubes containing $6 \mathrm{ml}$. of test medium and covered with loosely fitting glass caps were sterilized in the autoclave by heating until $10 \mathrm{lb}$. pressure was reached, at which point the gas was extinguished and the tubes allowed to cool. After inoculation, they were incubated in a water-bath at $\mathbf{2 5}^{\circ} \pm \mathbf{0} \cdot \mathbf{2}^{\circ}$.

* Formerly Industrial Fermentation. 


\section{Estimation of amount of yeast growth}

(a) When studying growth rate: the turbidity of the yeast suspension was measured by fitting the tubes into a wooden container placed in the optical beam of the Spekker absorptiometer (Northam \& Norris, 1951).

(b) When measuring growth for an assay: the yeast was brought into an even suspension by swirling the medium in the tubes and then pouring into a $1 \mathrm{~cm}$. glass cell. The turbidity was measured in the Spekker absorptiometer fitted with neutral grey-green filters no. H 508.

Dilution unit-turbidity calibration. The drum readings (turbidity) obtained using the Spekker were plotted against the cell concentration of yeast suspensions (dilution units) prepared by the dilution of portions of cultures grown under the usual experimental conditions.

Maintenance of cultures. K. brevis and $S$. pombe were subcultured monthly, or more frequently as required. The organisms were carried on malt agar slopes supplemented with a yeast extract, such as Difco Bacto yeast extract, at the rate of $2 \mathrm{~g}$. $/ 1$.

Inoculum. A loopful of a $24 \mathrm{hr}$. culture was suspended in $6 \mathrm{ml}$. of basal medium to give a turbidity in the tubes reading between $0 \cdot 15$ and $0 \cdot 25$ in the Spekker (i.e. approximately $\mathbf{0} \cdot \mathbf{2}-\mathbf{0} \cdot \mathbf{4} \mathrm{mg}$. dry weight of yeast $/ 6 \mathrm{ml}$.). For inoculation one drop $(20 \mu \mathrm{l}$.) of the suspension was added to each tube from a sterile Pasteur pipette.

\section{Development of the basal medium}

Unlike the other B vitamins, inositol is required in relatively large amounts by certain micro-organisms so that in the assay of a test preparation considerable amounts of other substances will be added to the assay medium. Consequently it is important that the basal medium should be as complete as possible with respect to these substances (Woolley, 1947). It was found that the medium of Emery et al. (1946) could be improved by increasing the concentration of vitamins and adding casein hydrolysate $(\mathbf{C H})$. Since test substances often have strong buffering effects, it was considered that the basal medium itself should be well buffered. Lactate buffer was found to be satisfactory for this purpose.

The modified basal medium, BM I + CH, corresponds to 'Basal medium III' described by Northam \& Norris (1951) with the exceptions that the lactate buffer was adjusted to $\mathrm{pH} 4.8$ and the concentration of the casein hydrolysate was diminished by one half.

Evidence that the basal medium BMI $+\mathrm{CH}$ was deficient in certain stimulatory substances required by $K$. brevis is given in Fig. $1 a$. Here the weight of yeast formed after $72 \mathrm{hr}$. incubation at a level of $12 \mathrm{mg}$. DYE/6 ml. of medium was approximately $80 \%$ greater than that formed in the presence of an optimal concentration of inositol (curves $A$ and $B$ ). The rate of growth of $K$. brevis was also markedly stimulated by DYE.

In the case of $S$. pombe, DYE had little effect on the rate of growth and increased the final extent of growth by only $10 \%$ (Fig. $1 b$, curves $A$ and $B$ ). 
As might be expected from these considerations, the result of the assay of inositol in DYE obtained using $S$. pombe $(3.59 \mathrm{mg}$./g.) was lower than that given by $K$. brevis $(\mathbf{3} .72 \mathrm{mg}$./g.) (Table 4$)$. In these circumstances the assay results could not be regarded with confidence, and therefore it was considered desirable to supplement the basal medium with an inositol-free preparation of yeast extract which would supply the unknown stimulatory substances.

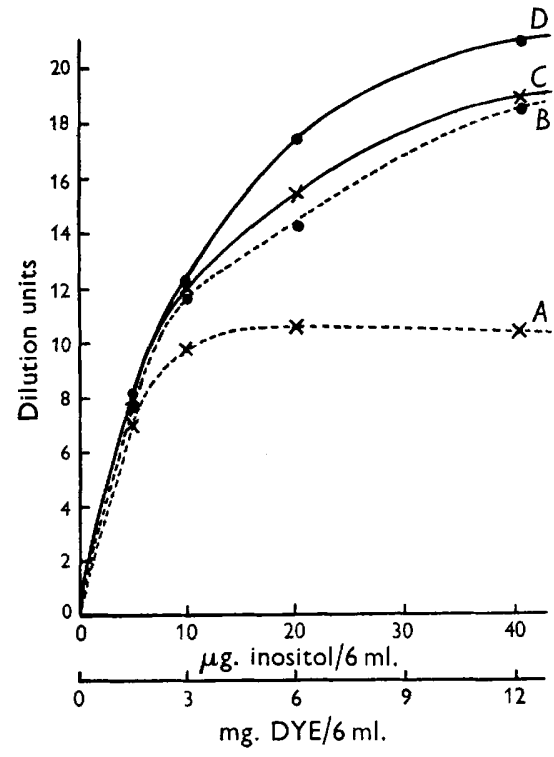

$a$

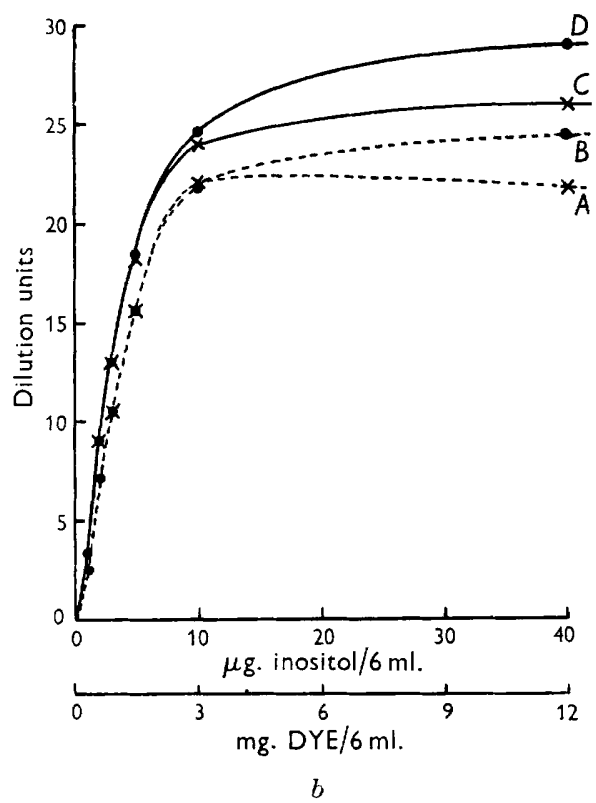

b

Fig. 1. Effect of the supplement on the response of $(a) K$. brevis and $(b) S$. pombe to inositol and DYE. - ..., BMI + CH; BM I Supp.; $x$, inositol;

, DYE.

Preparation of the supplement. As only a limited amount of DYE was available, a yeast extract produced by Norman Evans and Rais Ltd. (NEYE) was used.

Of the methods of fractionation attempted (Northam, 1951) the following was found to be satisfactory:

$9 \cdot 6 \mathrm{~g}$. NEYE were stirred for $10 \mathrm{~min}$. with a mixture of $760 \mathrm{ml}$. absolute ethanol and $40 \mathrm{ml} .2 \mathrm{~N}-\mathrm{NaOH}$. After centrifuging, the extract was neutralized with $5 \mathrm{~N}-\mathrm{HCl}$ and filtered through Whatman no. 1 filter-paper. The ethanol was removed by evaporating almost to dryness in vacuo at $30^{\circ}$. The residue was taken up in distilled water, adjusted to $\mathrm{pH} 4 \cdot 8$, filtered on Whatman no. 44 filter-paper, and made up to $100 \mathrm{ml}$. This supplement was added to the basal medium at the rate of $83 \mathrm{ml} . /$.

\section{Effect of the supplement on the growth of the organism}

At the lower levels of inositol $(0-5 \mu \mathrm{g}$. $/ 6 \mathrm{ml}$.) the growth of $K$. brevis reached a limit within $24 \mathrm{hr}$. in the presence of the supplement compared with $48 \mathrm{hr}$. in the unsupplemented medium. Moreover, the rate of growth in the presence 
of the test preparation (DYE) was the same as that at corresponding levels of the standard preparation (Fig. 2). This suggests that in the presence of the supplement, DYE is acting merely as a dilute solution of inositol, and that accurate assay results could be obtained at any time during the growth of the organism. The effect of the supplement on the final extent of growth of $\boldsymbol{K}$. brevis and $S$. pombe is shown in Fig. $1 a, b$ respectively. It was shown that the addition of casein hydrolysate to the supplemented basal medium had no effect on the growth of either organism at various levels of inositol. It was therefore omitted from the basal medium.

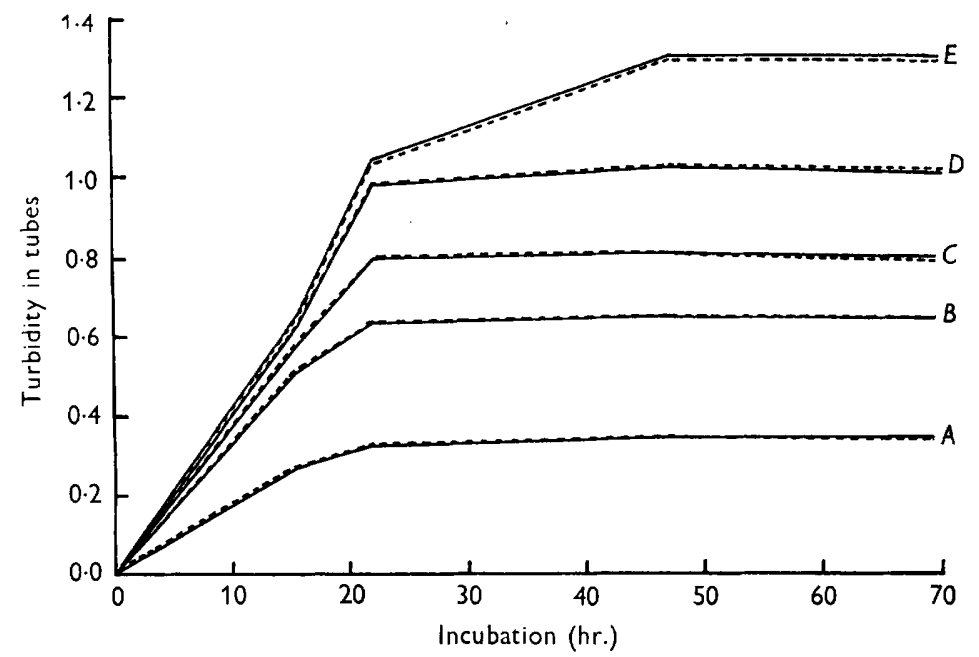

Fig. 2. Comparison of the response of $K$. brevis to inositol and corresponding levels of DYE in the supplemented basal medium. ——, $A=\mathbf{1} \cdot 0 ; B=\mathbf{2} \cdot 0 ; C=\mathbf{3 . 0} ; D=\mathbf{5} \cdot 0$; $E=10.0 \mu \mathrm{g}$. inositol $/ 6 \mathrm{ml}$. $\cdots .-A=290 ; B=580 ; C=870 ; D=1450 ; E=2900 \mu \mathrm{g}$. $\mathrm{DYE} / 6 \mathrm{ml}$.

\section{Design and analysis of the assay}

In order to compare assay values for the amount of inositol in Difco Bacto yeast extract (DYE) under the various experimental conditions described it was desirable to ascribe standard errors to these results. The need for the statistical analysis of microbiological assays has recently been emphasized by Finney $(1951 a)$. Such calculations can only be carried out conveniently when the response, or a metameter of the response, is a linear function of the dose. When the response was measured as the turbidity of the yeast suspension, the dose-response relationship was not linear. Log transformations did not help and other methods were sought.

(1) While there was reason to believe that a linear relationship existed between the weight of yeast formed and the dose, it was impracticable to weigh the yeast directly and a dilution method had to be used. Weightturbidity transformation curves were constructed by plotting dilution of yeast suspension (grown on a suitable medium) against the turbidities of these dilutions. Certain disadvantages however were inherent in the method: 
(a) The weight-turbidity relation of yeast grown at a concentration of, say, $40 \mu \mathrm{g}$. inositol $/ 6 \mathrm{ml}$. was not the same as that grown at $2 \mu \mathrm{g} . / 6 \mathrm{ml}$.

(b) Since the shape of the standard curve varied significantly from one experiment to another, it was not possible to apply a fixed transformation curve to a series of assays.

While this method gave satisfactory results on some occasions, on others there was a significant deviation from linearity which may have been due to fundamental faults in the assay, or to a systematic error in the construction of the transformation curve.

(2) A method of transformation first suggested by Ipsen (1941) and later by Finney $(1947 a, b)$ avoids the errors inherent in the construction of a weightturbidity transformation curve. In this method, an accurately determined standard curve is used as the transformation curve and the response in subsequent assays expressed in 'dose-equivalents' by reading off the doses corresponding to those responses from the transformation curve. Thus if a standard curve has the same shape as the transformation curve, then when the response is expressed in dose-equivalents, the regression of dose-equivalents upon dose will be linear and will pass through the origin.

Furthermore, if the test curve has the same shape as the standard curve (and this must be so if the assay is valid; Wood, 1945; Finney, 1945), then it will also become a straight line passing through the origin and the ratio of the slopes of the test and standard lines will give an estimate of the relative potency of the preparation. The deviations from linearity will provide a measure of the validity of the assay. However, the method does not overcome the difficulty that when the shape of the standard curve changes from one experiment to another the transformation curve is no longer applicable.

(3) For this reason, it was considered preferable to prepare a transformation curve with each assay. The usual standard curve can in fact, with suitable modification to the statistical analysis, be used as the transformation curve. If this curve is to be drawn by eye, gross errors must be avoided by arranging that the test and standard responses are near the same level. However, the disadvantages of this procedure may be avoided by having two points (referred to subsequently as a 'Bracket') close together on the standard curve on either side of the test responses. The response may then be expressed in dose-equivalents by simple calculation from the slope of the line joining these two points (the slope is given by $y / x$ in Figs. 3 and 5 ). The distance between these points is governed by two considerations, viz. $(a)$ they should be sufficiently far apart to permit an accurate determination of the slope between them; and $(b)$ they should be sufficiently close together for a straight line joining the points to deviate but slightly from the true curve.

The transformed data may be analysed according to the method of multiple regression given by Burn, Finney \& Goodwin (1950) with certain modifications to the statistical treatment (described below).

It must be emphasized, however, that this design and analysis can only be expected to give a close approximation to the correct result when the 
replication is good and the dose-response curve of a regular shape (Finney, 1951, private communication). The method described above for the design and analysis of assays will be referred to as the 'bracket transformation' method.

\section{Worked example of the 'bracket transformation' method}

The assay of DYE using $S$. pombe in the supplemented basal medium, BMI Supp., is here described as an example of the application of the bracket transformation method given above. The turbidity was measured in a $1 \mathrm{~cm}$. Spekker cell after $72 \mathrm{hr}$. incubation. The relationship between dose and response is shown in Table 1 and Fig. 3. The turbidities of the replicates at

Table 1. Response of S. pombe-turbidity measured in Spekker cell-to various doses of inositol and DYE after $72 \mathrm{hr}$. incubation in the supplemented basal medium BMI Supp.

One unit of standard preparation $\left(x_{s}\right)=0 \cdot 25 \mu \mathrm{g}$. inositol.

One unit of test preparation $\left(x_{t}\right)=75 \mu \mathrm{g}$. DYE.

Units inositol

$3 \cdot 6$

$4 \cdot 4$

$5 \cdot 6$

$6 \cdot 4$

$7 \cdot 6$

$8 \cdot 4$

Units DYE

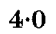

$6 \cdot 0$

$8 \cdot 0$

Spekker readings

\begin{tabular}{lllllll}
\hline \multicolumn{7}{c}{ Standard curve } \\
0.172 & 0.160 & 0.160 & 0.169 & 0.179 & & Mean \\
0.309 & 0.310 & 0.307 & 0.310 & 0.309 & 0.168 \\
0.477 & 0.485 & 0.488 & 0.475 & 0.479 & & 0.309 \\
0.568 & 0.580 & 0.577 & 0.589 & 0.575 & & 0.481 \\
0.710 & 0.702 & 0.718 & 0.713 & 0.708 & & 0.778 \\
0.790 & 0.787 & 0.798 & 0.798 & 0.782 & & 0.791 \\
0.261 & 0.270 & 0.257 & 0.290 & 0.270 & 0.269 & 0.269 \\
0.560 & 0.563 & 0.560 & 0.562 & 0.565 & 0.566 & 0.563 \\
0.779 & 0.787 & 0.775 & 0.786 & 0.782 & 0.786 & 0.782
\end{tabular}

each test level were expressed in dose-equivalents by simple calculation from the slopes of the appropriate brackets, and the replicates at each standard level were treated in the same way. Thus a turbidity ' $y$ ' may be expressed in dose-equivalents ' $Y$ ' from the equation

$$
\boldsymbol{Y}=x_{1}+\left(y-y_{1}\right)\left(\frac{x_{2}-x_{1}}{y_{2}-y_{1}}\right),
$$

where $x_{1}, y_{1}$ are the co-ordinates of the lower point and $x_{2}, y_{2}$ are the coordinates of the upper point of the standard bracket.

For example, the dose-equivalent corresponding to a turbidity of $\mathbf{0 \cdot 2 6 1}$ at the lowest test level (Table 1) was given by the equation

$$
Y=3 \cdot 6+(0 \cdot 261-0 \cdot 168)\left(\frac{(4 \cdot 4-3 \cdot 6)}{(0 \cdot 309-0 \cdot 168)}\right) \text {. }
$$

The transformed data are given in Table 2 and Fig. 4.

These data were analysed by the method of multiple regression (Burn et al. 1950, pp. 97-101) and the symbols used here are the same as those adopted by these authors. 
Table 2. Response of $\mathrm{S}$. pombe expressed in dose-equivalents

One unit of standard preparation $\left(x_{s}\right)=0.25 \mu \mathrm{g}$. inositol. One unit of test preparation $\left(x_{t}\right)=75 \mu \mathrm{g}$. DYE.

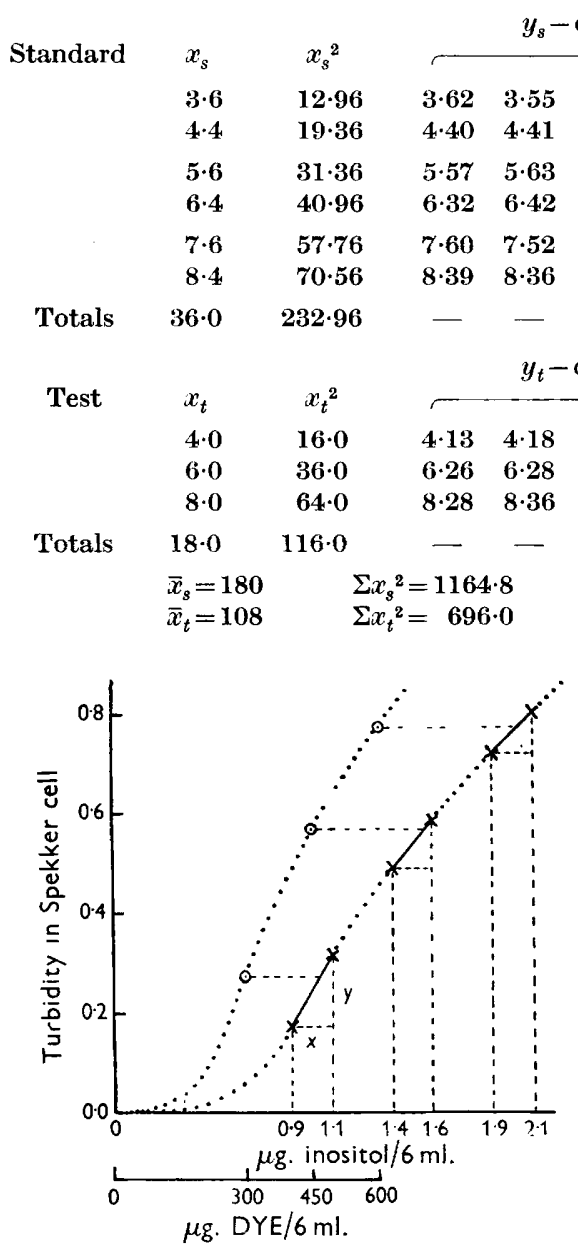

Fig. 3

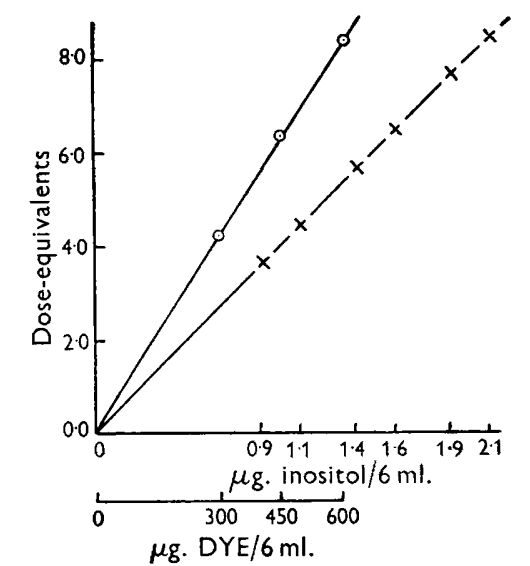

Fig. 4

Fig. 3. Response of $S$. pombe (turbidity measured in the Spekker cell) to various doses of inositol and DYE after $72 \mathrm{hr}$. incubation in BM I Supp. $\times$, inositol; $\odot$, DYE.

Fig. 4. Response of $S$. pombe expressed in dose-equivalents. $\times$, inositol; $\odot$, DYE.

Multiple regression. The test and standard lines may be represented by the bivariate equation

$$
\boldsymbol{Y}=a+b_{s} x_{s}+b_{t} x_{t},
$$

where $x_{s}$ (the dose of the standard preparation) is zero for all doses of the test preparation and $x_{t}$ (the dose of the test preparation) is zero for all doses of the standard. The regression coefficients may be evaluated from the equations

$$
\begin{aligned}
& b_{s} S x_{s} x_{s}+b_{t} S x_{s} x_{t}=S x_{s} y \\
& b_{s} S x_{s} x_{t}+b_{t} S x_{t} x_{t}=S x_{t} y
\end{aligned}
$$


where

$$
\begin{aligned}
S x_{s} x_{s} & =\Sigma x_{s}^{2}-\left(\Sigma x_{s}\right)^{2} / N \\
& =1164 \cdot 8-(180)^{2} / 48=489 \cdot 8, \\
S x_{s} x_{t} & =\Sigma x_{s} x_{t}-\left(\Sigma x_{s}\right)\left(\Sigma x_{t}\right) / N \\
& =0-(180)(108) / 48=-405, \\
S x_{t} x_{t} & =\Sigma x_{t}^{2}-\left(\Sigma x_{t}\right)^{2} / N \\
& =696 \cdot 0-(108)^{2} / 48=453, \\
S x_{s} y & =\Sigma x_{s} y-\left(\Sigma x_{s}\right)(\Sigma y) / N \\
& =1164 \cdot 8-(180)(292 \cdot 61) / 48=67 \cdot 5125, \\
S x_{t} y & =\Sigma x_{t} y-\left(\Sigma x_{y}\right)(\Sigma y) / N \\
& =725 \cdot 34-(108)(292 \cdot 61) / 48=66 \cdot 9675 .
\end{aligned}
$$

and

Substituting these values in equations (i) gives

The equation for ' $a$ ' is given by

$$
b_{s}=0.9974177, \quad b_{t}=1 \cdot 0395621 .
$$

$$
\begin{aligned}
a & =\bar{y}-b_{s} x_{s}-b_{t} x_{t} \\
& =292 \cdot 61 / 48-(0.9974177 \times 3 \cdot 75)-(1 \cdot 0395621 \times 2 \cdot 25) \\
& =0 \cdot 0167106 .
\end{aligned}
$$

The multiple regression equation therefore becomes

$$
Y=0.0167106+0.9974177 x_{s}+1 \cdot 0395621 x_{t} \text {. }
$$

Analysis of variance. The regression sum of squares is given by

$$
\begin{aligned}
b_{s} S x_{s} y+b_{t} S x_{t} y & =0.9974177 \times 67.5125+1.0395621 \times 66.9675 \\
& =136.955037 .
\end{aligned}
$$

The total, between doses, and error components are obtained by the usual statistical methods. However, since the dose means of the standard preparation have been forced to be co-linear it is necessary to remove a number of degrees of freedom two less than the number of doses for the standard from the total, between doses, and deviations components of the analysis of variance (Finney, $1951 b$ ).

The analysis of variance is given in Table 3.

Table 3. Analysis of variance

Adjustment for mean

Nature of variation

Regression

Deviations from regression

Between doses

Error

Total
1,783.76275

D.F. Sum of squares

$136 \cdot 95504$

0.00613

$136 \cdot 96117$

$0 \cdot 10038$

$137 \cdot 06155$

43
Mean square

$0 \cdot \overline{00306}$

$0 \cdot 00257$

Test of validity. The ratio of the deviations mean square to the error mean square

$$
F=\frac{0 \cdot 003064}{0 \cdot 002574}=1 \cdot 19
$$


With $n_{1}=\mathbf{2}, n_{2}=39$, this is clearly well below the significance level of $\mathbf{3} \cdot 24$, showing that the assay is statistically valid.

Relative potency. Unit dose of the test preparation is equal to $R$ units of the standard, where

$$
R=\frac{b_{t}}{b_{s}}=1 \cdot 0422536 .
$$

From the definition of the units of the two preparations at the head of Tables 1 and 2, $75 \mu \mathrm{g}$. DYE contains $0 \cdot 25 \times 1 \cdot 0422536 \mu \mathrm{g}$. inositol. Hence, $1 \mathrm{~g}$. DYE contains $\mathbf{3} \cdot \mathbf{4 7 4 1 8} \mathrm{mg}$. inositol.

Fiducial limits. The approximate variance of the potency ratio $R$ is given by the equation

$$
V(R)=\frac{s^{2}}{b_{s}^{2}} \times \frac{S x_{s} x_{s} \times 2 R S x_{s} x_{t}+R^{2} S x_{t} x_{t}}{S x_{s} x_{s} S x_{t} x_{t}-\left(S x_{s} x_{t}\right)^{2}}
$$

This expression is applicable only if the values of $g$ is small (say, less than $0 \cdot 1$ ) where

$$
\left.g=\frac{s^{2} t^{2} S x_{t} x_{t}}{b_{s}^{2}\left[S x_{s} x_{s} S x_{t} x_{t}-\left(S x_{s} x_{s}\right)^{2}\right.}\right]
$$

For good microbiological assays, $g$ will always be negligible (Wood \& Finney, 1946), and for this particular assay, $g=0 \cdot 0001$. Thus:

$$
\begin{aligned}
V(R) & =\frac{0 \cdot 002574}{(0 \cdot 9974177)^{2}} \times \frac{489 \cdot 8-810 \times 1 \cdot 0422536+(1 \cdot 0422536)^{2} \times 453}{489 \cdot 8 \times 453-(405)^{2}} \\
& =0 \cdot 0000061566 \\
s_{R} & =\sqrt{ }[V(R)]=0 \cdot 00248
\end{aligned}
$$

and

$$
R=1 \cdot 04225 \pm 0 \cdot 00248 \text {. }
$$

At 39 degrees of freedom and a probability of $0.05, t=2.023$ so that the fiducial limits, $2 \cdot 023 \times 0.00248$ on either side of $R$ became $1 \cdot 03723,1 \cdot 04727$. The estimated potency, $\mathbf{3} \cdot \mathbf{4 7 4} \mathrm{mg}$. inositol/g. yeast extract, was therefore assigned fiducial limits of $3.457,3.491 \mathrm{mg}$. inositol/g. Difco Bacto yeast extract.

A similar design and analysis was employed for assays using $\boldsymbol{K}$. brevis (Figs. 5 and 6 ) with the modification that the dose levels of the standard preparation were $0.75,1.05 ; 1 \cdot 65,1.95 ; 2.55,2.85 \mu \mathrm{g}$. inositol $/ 6 \mathrm{ml}$. (inositol solution made up at a concentration of $1 \mu \mathrm{g} . / \mathrm{ml}$.) and the test levels were 270,540 and $810 \mu \mathrm{g} . /$ tube (DYE solution at $300 \mu \mathrm{g} . / \mathrm{ml}$.).

\section{RESULTS}

The results for the assay of inositol in DYE under the various conditions discussed are given in Table 4 . The assay using $K$. brevis on the unsupplemented medium was computed using a dilution unit-turbidity transformation curve. Since the results were obviously significantly higher than that on the supplemented medium the assay was not repeated using the bracket transformation method.

On the supplemented medium, the assay using $K$. brevis was computed using the bracket transformation method with the six standard doses (i.e. three standard brackets) replicated six times and the three test doses replicated 
four times. This was modified to a more efficient design (Finney, 1951 b) for the $S$. pombe assays with the three standard brackets replicated five times and the three test doses replicated six times.

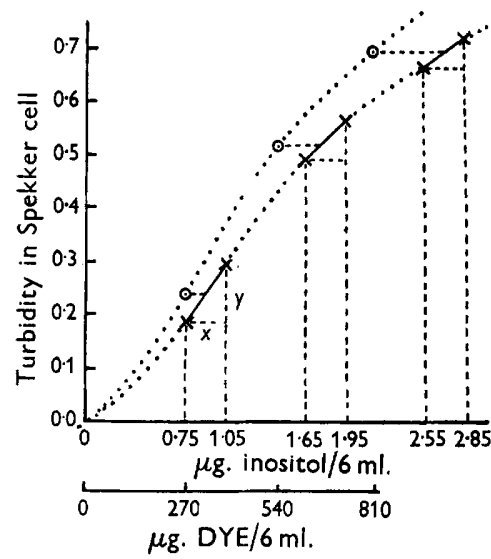

Fig. 5

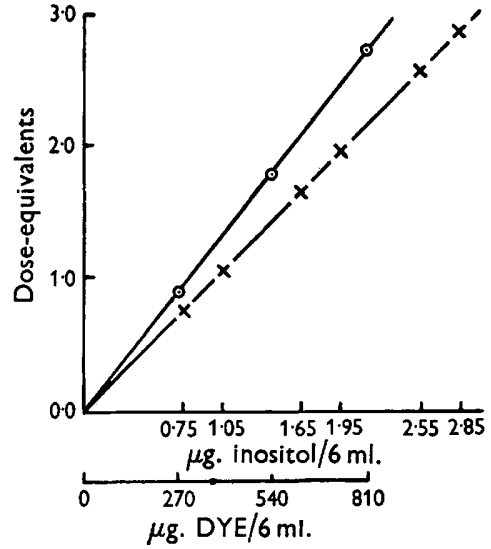

Fig. 6

Fig. 5. Response of $\boldsymbol{K}$. brevis (turbidity measured in Spekker cell) to various doses of inositol and DYE after 72 hr. incubation in BM I Supp. $\times$, inositol; $\odot$, DYE.

Fig. 6. Response of $K$. brevis expressed in dose-equivalents. $\times$, inositol; $\odot$, DYE.

Table 4. Comparison of assay results

\begin{tabular}{|c|c|c|c|c|c|}
\hline \multirow[b]{2}{*}{ Organism } & \multirow[b]{2}{*}{ Basal medium } & \multirow{2}{*}{$\begin{array}{l}\text { Period of } \\
\text { incubation } \\
\text { (hr.) }\end{array}$} & \multirow{2}{*}{$\begin{array}{l}\text { Potency } \pm \text { s.F. } \\
\text { Fiducial limits } \\
\quad(P=0.95)\end{array}$} & \multicolumn{2}{|c|}{ Test of validity } \\
\hline & & & & $F$ & $\boldsymbol{P}$ \\
\hline \multirow[t]{4}{*}{ K. brevis } & BM I Supp. & $24^{*}$ & $\begin{array}{l}3 \cdot 441 \pm 0 \cdot 025 \\
3 \cdot 39-3 \cdot 49\end{array}$ & $0 \cdot 54$ & $>0 \cdot 20 \ddagger$ \\
\hline & & $72 *$ & $\begin{array}{l}3 \cdot 461 \pm 0 \cdot 023 \\
3 \cdot 41-3 \cdot 51\end{array}$ & $1 \cdot 32$ & $>0.20 \ddagger$ \\
\hline & & $74 \dagger$ & $\begin{array}{l}3 \cdot 441 \pm 0 \cdot 021 \\
3 \cdot 40-3 \cdot 48\end{array}$ & $0 \cdot 68$ & $>0.20 \ddagger$ \\
\hline & $\mathrm{BMI}+\mathrm{CH}$ & $72 \dagger$ & $\begin{array}{l}3 \cdot 723 \pm 0 \cdot 019 \\
3 \cdot 68-3 \cdot 76\end{array}$ & 8.45 & $<0.001$ \\
\hline \multirow[t]{4}{*}{ S. pombe } & BMI Supp. & $48 *$ & $\begin{array}{l}3 \cdot 462 \pm 0 \cdot 018 \\
3 \cdot 42-3 \cdot 50\end{array}$ & 0.45 & $>0 \cdot 20 \ddagger$ \\
\hline & & $70 *$ & $\begin{array}{l}3 \cdot 458 \pm 0.016 \\
3.42-3.49\end{array}$ & 0.77 & $>0 \cdot 20 \ddagger$ \\
\hline & & $72 \dagger$ & $\begin{array}{l}3 \cdot 474 \pm 0 \cdot 008 \\
3 \cdot 46-3 \cdot 49\end{array}$ & $1 \cdot 19$ & $>0 \cdot 20 \ddagger$ \\
\hline & $\mathrm{BMI}+\mathrm{CH}$ & $73 \dagger$ & $\begin{array}{l}3 \cdot 586 \pm 0 \cdot 012 \\
3 \cdot 56-3 \cdot 61\end{array}$ & $6 \cdot 61$ & $0.01-0.001$ \\
\hline
\end{tabular}

The potency is expressed in $\mathrm{mg}$. inositol/g. DYE.

* Turbidity measured in the tubes.

+ Turbidity measured in Spekker cell.

+ Assay statistically valid.

\section{DISCUSSION}

It is evident from Table 4 that addition of the supplement to the basal medium reduced the apparent inositol content of Difco Bacto yeast extract obtained from assays using either $K$. brevis or S. pombe. (While estimates of 
potency and fiducial limits of statistically invalid assays may not be strictly accurate it is likely that these estimates are sufficiently accurate for the purposes of comparison.) From previous considerations the lower value would be expected to give a truer estimate of the potency. The observation that assay values obtained using $K$. brevis and $S$. pombe in the supplemented medium do not differ significantly provides strong support for the reliability of assays carried out under these conditions.

The choice of organisms for subsequent assays is governed by the following considerations:

(a) Assays using $K$. brevis and $S$. pombe may be completed after 24 and $48 \mathrm{hr}$. respectively without loss of accuracy.

(b) The $95 \%$ fiducial limits of assays using $S$. pombe were approximately $\pm 0.5 \%$ as compared with $\pm 1 \%$ for $K$. brevis.

(c) S. pombe requires less inositol than $K$. brevis to produce a given response, and although this does not affect the precision of the assay (Wood, 1946) it may be advantageous in that less test material (and therefore less interfering substances) would be added to the assay medium.

The method is being applied successfully to cereals and cereal products in these laboratories.

The authors are indebted to Dr N. S. Cutts for contributions to the development of the transformation method; to Dr D. J. Finney, Oxford University, for assistance with the statistical matter; and to Dr M. Horwood, of Messrs Norman Evans and Rais Ltd., Wilmslow Road, Cheadle, Cheshire, for samples of yeast extract.

This contribution, carried out under a grant from the Department of Scientific and Industrial Research, formed part of a thesis submitted by one of the authors (B. E. N.) for the degree of Ph.D. (Birm.).

\section{REFERENCES}

Barton-Wright, E. C. (1946). Practical Methods for the Microbiological Assay of the Vitamin B Complex and Essential Amino-Acids. London: Ashe Laboratories.

Burkholder, P. R., MCVeigh, L. \& Moyik, D. (1944). Studies of some growth factors of yeasts. J. Bact. 48, 385 .

Burn, J. H., Finney, D. J. \& Goodwin, L. G. (1950). Biological Standardization. London: Oxford University Press.

Emery, W. B., McLeod, N. \& Robinson, F. A. (1946). Comparative microbiological assays of members of the vitamin $B$ complex in yeast and liver extracts. Biochem. J. 40, 426.

Finney, D. J. (1945). The microbiological assay of vitamins: the estimate and its precision. Quart. J. Pharm. 18, 77.

Finney, D. J. (1947a). The principles of biological assay. J. R. statist. Soc. (Suppl.), $9,46$.

Finney, D. J. (1947b). Statistical aspects of microbiological assays. Biochem. $J$. 41, v.

Finney, D. J. $(1951 a)$. The statistical analysis of slope-ratio assays. J. gen. Microbiol. 5, 223.

Ipsen, J. (1941). Contributions to the Theory of Biological Standardization. Copenhagen: Nyt Nordisk Forlag, Arnold Busck.

Northam, B. E. (1951). The Microbiological Assay of Inositol. Ph.D. thesis, Birmingham University. 
Northam, B. E. \& Norris, F. W. (1951). Growth requirements of Schizosaccharomyces octosporus, a yeast exacting towards adenine. J. gen. Microbiol. 5, 502.

Ridyard, H. N. (1949). High accuracy and high speed pipettes and associated apparatus. Analyst, 74, 24.

Williams, R. J., Stout, A. K., Mitchell, H. K. \& McMahon, J. R. (1941). Assay method for inositol. Univ. Texas Publ. no. 4137, 27.

Woon, E. C. (1945). Calculation of the results of microbiological assays. Nature, Lond. 155, 632.

Woon, E. C. (1946). The theory of analytical procedures with special reference to microbiological assays. Analyst, 71, 1.

Woon, E. C. \& Finney, D. J. (1946). The design and statistical analysis of microbiological assays. Quart. J. Pharm. 19, 112.

Woolley, D. W. (1941). A method for the estimation of inositol. J. biol. Chem. 140, 453.

Woolley, D. W. (1947). The determination of inositol. Biol. Symp. 12, 279.

(Received 19 March 1952) 